\title{
Considerações sobre a Influência dos Valores e Direitos Fundamentais no Âmbito da Teoria Processual $^{1}$
}

\section{Considerations about the Influence of Values and Fundamental rigths over the Procedural law Theory}

Eduardo de Avelar Lamy

Universidade Federal de Santa Catarina, Florianópolis, SC, Brasil

\begin{abstract}
Resumo: Trata-se de estudo sobre a influência dos direitos fundamentais e dos seus respectivos valores junto às normas que concernem ao direito processual e a sua teoria, especialmente no sistema jurídico brasileiro. Portanto, defendeu-se ao final, por meio do estudo, a possibilidade de fundamentações valorativas na interpretação e na aplicação das normas processuais.

Palavras-chave: Direitos Fundamentais. Valores. Teoria Processual. Processo. Influência.
\end{abstract}

\begin{abstract}
The study analyses the influence of the norms that regulate the fundamental rights and it's values began to have over norms that concern about procedural law and about procedural law theory, especially before the Brazilian legal system, discussing, at the final part, the possibility of considering values in procedural norms.
\end{abstract}

Keywords: Fundamental Rights. Values. Procedural Law Theory. Process. Influence.

\section{Introdução}

Ao longo de sua história, o Brasil teve dificuldades para estabelecer um Estado de Direito democraticamente regido, politicamente estável e ideologicamente amadurecido.

1 Recebido em: 13/5/2014

Revisado em: 4/8/2014

Aprovado em: 11/9/2014 
Diante desse fato, torna-se necessário conscientizar os operadores jurídicos e os estudiosos do processo, formadores de opinião, para pensarem o seu conteúdo na perspectiva valorativa dos direitos fundamentais; para serem sujeitos do pensamento ideológico, ao invés de servirem à manipulação que o ingênuo pressuposto das imparcialidades científica e valorativa proporciona no âmbito da supostamente pura dogmática processual.

O reconhecimento da existência de valores juridicamente consideráveis e de direitos fundamentais oriundos, especialmente do respeito à dignidade da pessoa humana, passou a ser amplamente difundido pelos ordenamentos ocidentais, mormente após o holocausto e a Segunda Guerra Mundial.

Embora frequentemente desconsiderado pela teoria geral do direito, ${ }^{2}$ tal reconhecimento trouxe para a ciência jurídica uma nova preocupação, ligada tanto aos valores albergados pelo ordenamento quanto ao encontro dos métodos adequados às fundamentações decisórias valorativas.

Desse modo, este estudo objetiva analisar, nessa perspectiva, aspectos cujos valores albergados pela temática dos direitos fundamentais estejam influenciando o desenvolvimento de uma teoria processual, ou ao menos de um pensamento processual ideologicamente consciente.

\section{A Influência dos Direitos Fundamentais no Âmbito do Processo}

\subsection{O Pensamento Valorativo Processual}

Desde a década de 1970, os cientistas vêm divulgando a influência dos valores fundamentais sobre o desenvolvimento dos sistemas de justiça e sobre o direito processual, preocupando-se com a morosidade e a efetividade da jurisdição, bem como com o cumprimento do seu papel

\footnotetext{
2 A própria Teoria "Pura" do Direito, construiu uma verdadeira fortaleza em torno da validade das normas jurídicas, tendo como pressuposto a Norma Fundamental que constitui o ápice da hermética pirâmide, despida de considerações valorativas, arquitetada por Kelsen em Teoria Pura do Direito (1997).
} 
perante a sociedade, o que, inicialmente, influenciou a ideia de Acesso à Justiça. (CAPPELLETTI; GARTH, 1988)

Por meio de pesquisa empírica eminentemente preocupada com o ser processual, a temática do Acesso à Justiça dedicou-se ao amplo reconhecimento do direito de estar em juízo para a proteção democrática dos mais variados bens jurídicos.

A disseminação da ideologia social-democrata, que influenciou consideravelmente a própria mutação do Estado Liberal, à qual o surgimento e o reconhecimento dos princípios e direitos fundamentais estiveram intimamente ligados, repercutiu, portanto, junto ao processo e às estruturas da prestação jurisdicional.

Percebe-se, do mesmo modo, que o caráter ideológico social da constituição de 1988 tem provocado a análise da função social dos mais variados institutos e ramos da ciência jurídica. ${ }^{3}$

No direito processual, os cientistas tendem a concordar, hoje, com a necessidade de identificar-se uma teoria do processo adequada aos ditames constitucionais, e, portanto, pensada a partir destes e não apenas oriunda dos institutos clássicos da relação jurídica processual, ação, jurisdição e defesa. ${ }^{4}$

Demonstram a importância da Constituição Federal para o atual processo civil brasileiro as previsões constantes de vários incisos do seu artigo $5^{\circ}$ : inciso XXXV, referente à norma principal da inafastabilidade do controle jurisdicional e à busca pela efetividade do processo; inciso LIV, sobre as normas principais da ampla defesa e do contraditório; incisos LIII e XXXVII, referentes à norma principal do juiz natural; inciso LXXVIII (trazido pela EC 45) concernente à duração razoável e também ligado à efetividade do processo; inciso LVI, a respeito da inadmissibilidade das provas

\footnotetext{
3 Ver o artigo de Calmon de Passos, Função Social do Processo. (2002).

4 Nesse sentido, Figueira Júnior (3003, p. 119): “[...] conseguimos extrair dessa inovação o sutil esboço de um processo civil verdadeiramente novo, hábil a representar o instrumento do terceiro milênio, voltado ao equacionamento do trinômio valorativo identificado pela celeridade, segurança e justiça da decisão".
} 
ilícitas, dentre outros, bem como as regras da obrigatoriedade de motivação e da publicidade das decisões judiciais (CF, art. 93, IX).

A interpenetração entre constituição e processo ensejou, inclusive, a conclusão de (NERY JÚNIOR, 2000) para quem se tornou mais clara, após 1988, a existência dos ramos do Direito Constitucional Processual e do Direito Processual Constitucional, de modo que o primeiro ramo referir-se-ia aos institutos do processo inseridos na atual constituição, enquanto o segundo ramo diria respeito aos princípios eminentemente processuais diretamente aplicados à chamada jurisdição constitucional. ${ }^{5}$

Com efeito, por meio da atual constituição, o nosso direito passou a dedicar maior atenção a interesses que vão além da solução dos litígios subjetivamente considerados, reconcebendo inúmeros institutos, dentro e fora da ciência processual, tal a influência dos direitos fundamentais sobre os fenômenos de interpretação, produção e aplicação do direito.

As constituições políticas contemporâneas não têm mais apenas o objetivo de delimitar a atividade do estado em face do cidadão considerado individualmente. Em razão do conflito de interesses de certas coletividades, depende-se do devido processo legal para atingir as soluções esperadas. Pela influência dos direitos fundamentais, nas palavras de (GUERRA FILHO, 2003, p. 26): “[...] o processo torna-se um instrumento privilegiado de participação política e exercício permanente da cidadania." ${ }^{\circ}$

\footnotetext{
5 Afirma Nelson Nery Jr. (2000 p. 20 e 21) que "[...] o Direito Processo Processual Civil, ramo do direito público, é regido por normas que se encontram na Constituição Federal e na legislação infraconstitucional. Existem, também, institutos processuais cujo âmbito de incidência e procedimento para sua aplicação se encontram na própria Constituição. Naturalmente, o direito processual se compõe de m sistema uniforme, que lhe dá homogeneidade, de sorte a facilitar sua compreensão e aplicação para a solução das ameaças e lesões a direito. Mesmo que se reconheça essa unidade processual, é comum dizer-se didaticamente que existe um Direito Constitucional Processual, para significar o conjunto das normas de direito processual que se encontra na Constituição Federal, ao lado de um Direito Processual Constitucional, que seria a reunião dos princípios para o fim de regular a denominada jurisdição constitucional. Não se trata, portanto, de novos ramos do direito processual".

6 Segundo o autor, o processo se torna essencial para "solucionar as colisões entre interesses diversos de certas coletividades entre si e com interesses individuais ou estatais, tão variadas e imprevisíveis em sua ocorrência”.
} 
Desse modo, embora até bem pouco tempo atrás fosse muito comum aplicar-se e interpretar-se determinado ramo do direito levando-se em conta apenas a principal lei ordinária que o regulamentava, como disse (NERY JUNIOR, 2000) ${ }^{7}$, a atual influência dos direitos fundamentais sobre o direito processual tem contribuído significativamente para a paulatina e profunda modificação de seus elementos essenciais teóricos e operativos.

Tradicionalmente, aceitando a existência de uma relação jurídica instrumental diferenciada das relações jurídicas de direito material, o processo é conceituado como sendo o meio através do qual a jurisdição, substituindo-se às partes, diz o direito. Trata-se de um conceito preocupado com a carga declaratória das decisões jurisdicionais, pois se a tutela jurisdicional é aquela que "diz o direito", equipara-se a atividade eminentemente jurisdicional à tarefa de declarar qual das partes tem razão, afirmar qual das partes está certa, mas não à tarefa de executar essa razão no mundo dos fatos: o velho "ganha mas não leva".

Tal concepção de jurisdição tem motivos históricos bastante compreensíveis. No direito romano, havia, inicialmente, uma divisão entre os interditos e as actios. Enquanto os interditos eram medidas sincréticas e sumárias que detinham cognição e execução simultâneas, tendo, basicamente, caráter mandamental ou executivo lato sensu e sendo julgados pelos pretores, as actios consistiam em medidas fundamentalmente cognitivas de modo exauriente, que possuíam caráter declaratório, constitutivo ou mandamental, e eram julgadas pelos jurisconsultos, como explicita. (BEDAQUE, 2003) ${ }^{8}$

7 Segundo Guerra Filho (2003, p. 26): “Era muito comum, pelo menos até bem pouco tempo, interpretar-se e aplicar-se determinado ramo do direito tendo-se em conta apenas a lei ordinária principal que o regulamentava. Assim, o civilista via no Código Civil a única norma que deveria ser consultada na solução de problemas naquela área, o mesmo ocorrendo com o processualista (civil, penal e trabalhista), com o penalista, com o comercialista".

8 Ensina Bedaque (2003, p. 30): "Parece possível estabelecer comparação entre procedimentos do direito atual que se iniciam com atos decisórios, pedidos de cognição sumária e coercitivos, e os interditos do processo romano. Estes consistiam em ordem emitida pelo magistrado, impondo certo comportamento a uma pessoa privada, a pedido de outra. Essa forma de tutela, emanada do poder de imperium do magistrado, abrangia 
Ocorre que, mesmo no império romano, a realidade fática trouxe a necessidade de aprimorarem-se os meios à tutela dos fins, concepção instrumental essa que resultou no fenômeno da unificação entre interditos e actios através da publicização da actio e da extinção do processo formulário entre os séculos III a V d.C, período que ficou conhecido como o do Baixo Império, imediatamente antecedente à queda do Império Romano do Ocidente, nos quais muitas instituições se desenvolveram em meio, no entanto, à corrosão do sistema escravista.

Infelizmente, o fenômeno da unificação foi ignorado pelos glosadores durante a Idade Média, o que resultou no ressurgimento, junto ao direito canônico, da dualidade entre actios e interditos, e na lógica de que a essência da atividade jurisdicional está em declarar-se o direito, concepção essa que ganhou ênfase pela influência daquele momento histórico, considerada a importância da figura paterna da divindade.

Explica-se. A figura do juiz, no imaginário coletivo, assemelhou-se à figura de Deus-Pai, pois o julgador declara, aos olhos da sociedade, o que é justo e o que é injusto, o que se pode e o que não se pode fazer, nas mais diversas lides que lhe são submetidas. O significado da figura paterna, especialmente pelos estudos de (FREUD, 1980, p. 3.014 e 3.015.), demonstra, desde a infância, a distinção entre o que é certo e o que é errado, entre o que se pode e o que não se pode fazer: a noção de limites; a noção de até onde se pode ir.

Acredita-se, devido à influência do direito canônico sobre o nosso sistema judicial, na existência de uma concepção vetusta de tutela jurisdicional, que não compreende a segurança jurídica como a previsibilidade das decisões do poder judiciário, mas sim como o credo no fato de que o juiz é quem pode dizer o que é certo e o que é errado: o credo no fato de

a grande maioria das relações da vida envolvendo direitos absolutos. Já os direitos obrigacionais, versando indenização, eram amparados pela actio, com juízo privado. Só a primeira admitia execução específica. No direito romano havia, portanto, dois sistemas de processo civil. Em um deles era possível a obtenção de ordem liminar, até sem a presença da parte contrária e mediante cognição sumária das afirmações do autor, se feitas conforme o édito. No outro havia pleno contraditório desde o primeiro momento, não era possível a emissão de mandado e a atividade cognitiva era privada". 
que o juiz declara o que é certo e que este é o verdadeiro caráter da atividade eminentemente jurisdicional.

Desse modo, o surgimento e o próprio desenvolvimento do direito processual, através do reconhecimento da tese de (VON BULLOW, 1964), acerca da existência de uma relação jurídica processual distinta da relação jurídica de direito material, foi limitado pela concepção excessivamente declaratória e, portanto, paternalista, preocupada com o mito da segurança jurídica (neste caso, não identificada com a previsibilidade das decisões, mas sim com o seu acerto), o que resultou na ordinarização de procedimentos e na clássica adoção da classificação trinária das ações, bem como na pouca consideração à feição executiva da tutela jurisdicional e na rejeição à especialização e à adaptação de procedimentos para a efetiva tutela dos direitos. Hoje, entretanto, pensando o direito processual na perspectiva dos direitos fundamentais, chega-se à conclusão de que o próprio elemento constituído pela jurisdição não precisa ser inerente ao conceito de processo, como também de que não é apenas a carga declaratória que interessa ao escopo da jurisdição, mas principalmente a produção de resultados efetivos através do processo.

Nesse sentido, (FAZZALARI, 1966, p. 1.068 e 1.069) demonstra que a redução e a identificação do fenômeno processual para com o exercício da função jurisdicional eminentemente declaratória trata-se de uma consequência histórica do fato de que o direito processual desenvolveu-se, inicialmente, no seio da jurisdição. No entanto, atualmente tal circunstância não autoriza a limitação e muito menos a identificação do processo para com a jurisdição.

Com efeito, alguns dos acontecimentos que mais marcaram o século passado - como as guerras mundiais - trouxeram para o processo de positivação e aplicação do direito processual, uma conscientização valorativa que parecia ter sido esquecida, e que necessita ser estudada em conjunto com os institutos basilares do direito processual. 
Interpreta-se nesse sentido a temática da instrumentalidade do processo, bastante difundida pelos estudos de (DINAMARCO, 2003) ${ }^{9}$, concepção essa que acredita-se necessita reconhecer sua carga evidentemente valorativa, acerca da interpretação do direito positivo. Percebe-se, portanto, que essa imbricação entre dogma e valor se deu, especialmente, a partir do âmbito constitucional, iniciando uma nova era no desenvolvimento do sistema jurídico.

Entretanto, encontrar respostas para as questões mais complexas é tarefa cuja essência se situa entre o raciocínio ilimitado da moral valorativa e o universo da dogmática tradicional, conjugados. As decisões mais importantes no estado democrático de direito contemporâneo sofreram considerável re-direcionamento dos poderes legislativo e executivo em direção ao poder judiciário. Daí o papel essencial das cortes constitucionais, de atribuição tanto jurídica quanto política, na estrutura desses estados.

Admite-se obviamente, portanto, o papel inclusive político do poder judiciário. O pensamento dos diferentes ramos do direito na perspectiva dos direitos fundamentais leva à admissão, à assunção explícita, que passa a ocorrer, por diferentes estudiosos da dogmática jurídica, como foi o caso de (CALMON DE PASSOS, 2004, p. 54), acerca da concepção valorativo-ideológica de suas ideias, o que obviamente não retira a importância modelar, estrutural, portanto, do conhecimento dogmático teórico e prático.

Não se trata de subordinar o direito ao critério moral da pessoa humana que exerce a função judiciária, mas sim de admitir a realidade causal segundo a qual a própria decisão de buscar as respostas que o sistema jurídico fornece em detrimento dos valores pessoais do julgador, é, de fato, oriunda de uma escolha valorativo-ideológica deste, cuja real ocorrência não se pode ignorar, ${ }^{10}$ seja qual for a instância judiciária.

9 Conforme afirma Dinamarco (2003, p. 200): "Mas as explicações meramente jurídicas da destinação do processo pecam justamente por deixarem na sombra o valor humano perseguido através do exercício da jurisdição. Saia-se do plano do direito e passe-se ao da sociedade ao qual ele se destina, e então sentir-se-á que seria inteiramente inaceitável e mesmo logicamente sem explicação a busca da paz entre pessoas num caso concreto, sem saber se elas estão em real conflito".

10 A Teoria Material da Constituição abriu caminho para o pensamento de autores como Peter Haberle, que inovaram a compreensão do fenômeno constitucional sob a ótica da 
Os verdadeiros pensadores são aqueles que procuram analisar a realidade através da harmonização de ideias que, nas palavras de (BECKER, 2004, p. 11),

[...] parecem alheias ou indiferentes a uma específica realidade, buscando a conciliação entre homens que se imaginam inimigos ou estrangeiros em razão das teorias que esposaram. A solidão de uma linguagem - mesmo da linguagem pura de uma ciência - ainda padece do defeito de ser solitária. A solidão das diversas linguagens

chamada Nova Hermenêutica buscando resgatar o seu papel normatizador, enfraquecido com a preponderância de vários matizes do poder sobre a Lei Fundamental. Já na teoria de Konrad Hesse, exposta na obra A Força Normativa da Constituição, preocupa-se em destacar a importância desta força normativa através da análise da relação entre os fatores reais de poder e a Constituição. A força ativa da constituição não seria somente a de regular o presente, mas também capaz de construir o futuro com base na imposição de tarefas representando a sua vontade. Esta vontade da constituição se originaria da necessidade de uma ordem normativa superior à simples ordem legitimada pelos fatos, eficaz contra a vontade humana, e condicionante desta. A reforma da constituição através de emendas não é a melhor opção do ponto de vista do autor, pois enfraquece o texto constitucional, deixando-o ao sabor das mudanças sociais. Assim, a constituição não estaria apta a impor comportamentos, ante a sua fragilidade. Surge então a opção da mutação constitucional através da interpretação. Para tanto, seria necessária a concepção de constituição como sistema aberto. Complementando os estudos de Hesse, Peter Haberle defende que a interpretação da constituição é um processo aberto e dinâmico, no qual participam não somente os intérpretes tradicionais, normalmente os juízes, mas também toda a sociedade, pois quem vive a norma acaba por interpretá-la ou pelo menos co-interpretá-la, já que a interpretação constitucional diz respeito a todos, consistindo um elemento caracterizador da "sociedade aberta". Assim, a interpretação da constituição seria um processo aberto, que considera a constituição como uma realidade pública constituída (verfassten Wirklichkeit und Öffentlichkeit). A constituição, nesse sentido, seria um espelho da realidade, necessitando ser interpretada conforme as necessidades sociais concretas de efetivação das disposições constitucionais e dos direitos fundamentais. Para tanto, o autor distingue a interpretação em sentido estrito e em sentido lato. A primeira utiliza os métodos tradicionais de interpretação, sendo efetuada pelos intérpretes tradicionais, entre eles os juízes e os doutrinadores, enquanto a interpretação em sentido lato, que no seu entendimento é a verdadeira interpretação, é efetuada pela sociedade pluralista, oriunda de um processo aberto, dinâmico e democrático. $O$ advento da nova hermenêutica é muito importante para a delineação de uma nova teoria geral do processo, haja vista trataremse de conclusões ligadas à necessária conscientização dos intérpretes tradicionais acerca da abertura da constituição e das necessidades sociais de resultados através do processo. 
cria distorções. A confusão a respeito de uma verdade não se origina na multiplicidade das linguagens, mas no círculo fechado da linguagem solitária, que leva a crer que - ela mesma - seria um universo e a única pensável. ${ }^{11}$

Dessa forma, acredita-se que para melhor destrinchar os temas mais desafiadores, é necessário haver comunicação entre as diferentes linguagens da ciência jurídica; mais conhecimento e fundamentação dogmáticos junto à zetética e maior profundidade crítica, inclusive valorativa e ideológica, junto ao estudo da dogmática. E é também nesse sentido que a incidência dos direitos fundamentais sobre o direito processual tem contribuído significativamente para a sua transformação, tanto sob o ponto de vista eminentemente teórico quanto sob o aspecto prático-operativo.

Trata-se de uma forma de pensar o direito processual como instrumento para a efetivação do direito material, passando pela reconceituação de vários dos institutos essenciais do processo, o que justificaria, até mesmo, definirem-se as bases para uma nova teoria geral da disciplina: uma teoria que não esteja fundada apenas nos institutos da relação jurídica processual, da ação, da jurisdição e da defesa, mas também, e principalmente, nos direitos fundamentais, reestruturando o processo a partir dos seus princípios constitucionais sem, contudo, deixar de reconhecer importância aos institutos.

Nesse cenário, a modificação do conceito de tutela jurisdicional é tema que tem importantes consequências para o estudo dos mais variados temas em Direito. Isso pelo fato de que, aqueles que, consoante a concepção tradicional, veem a tutela jurisdicional apenas como a resposta obtida através da jurisdição, tendem a entender que se deve negar a adequada tutela jurisdicional necessitada para o exercício do direito material da par-

\footnotetext{
11 Diz, ainda, Becker (2004, p. 111): “O desejo da fidelidade a um velho mestre induz o jurista a atraiçoar a verdade. $\mathrm{O}$ fato de uma doutrina perdurar a mais de dez séculos não é argumento que prove a sua veracidade, pois aquela doutrina pode simplesmente ser um erro que tenha perdurado dez séculos mais que os outros erros. Se, de um lado, se critica a originalidade juvenil, não deve ser esquecido que, do outro lado, encontra-se a obstinação senil. O conflito entre os velhos e os jovens é a doença crônica das civilizações fundada sobre o argumento da autoridade".
} 
te, quando o meio processual utilizado for diverso daquele que o julgador acredita ser correto.

No entanto, a tutela jurisdicional é muito mais do que uma resposta da jurisdição ao pleito que lhe é formulado, pois o direito contemporâneo, processual ou material, encontra-se impregnado pelos valores humanitários. Tais valores conclamam cada indivíduo, especialmente os operadores jurídicos, para um compromisso em relação à solução dos conflitos. No plano processual, a técnica inibitória, bastante difundida no Brasil pelos estudos de (MARINONI, 1998), ao buscar prevenir o ilícito e, consequentemente, proteger todo o ordenamento jurídico, é um exemplo que demonstra essa conscientização coletiva a cada dia mais necessária.

É preciso haver maior compromisso da comunidade do direito frente à resolução prática e efetiva dos problemas que lhe são colocados. A tutela jurisdicional, hoje, não pode mais significar apenas uma resposta aos pedidos que lhe são feitos. É necessário haver um compromisso por parte daqueles que a requerem e que a prestam para com os seus resultados práticos. Trata-se, portanto, de uma conscientização a ser trabalhada junto aos próprios especialistas, muitas vezes excessivamente apegados aos argumentos e fundamentos oriundos do rigor técnico do processo.

Nesse diapasão, a aplicação, por exemplo, da norma principal (princípio, na acepção tradicional) da fungibilidade junto aos meios processuais - constituídos por normas não principais (regras), possibilita melhor obtenção de resultados práticos através da jurisdição na vida dos litigantes, coadunando-se com a realidade forense que demanda interpretar-se a constituição e o ordenamento jurídico conforme a necessidade social e a melhor operabilidade do instrumento constituído pelo processo.

Desse modo, atualmente, o processo não é mais apenas um meio formal preocupado com o seu respeito acima do próprio direito material, através do qual apenas a jurisdição diz o direito, limitando-se a responder aos pleitos que lhe são formulados. Hoje, o direito processual deve ser conceituado como o resultado da operação de um núcleo de direitos fundamentais, especialmente a ampla defesa e o devido processo legal, que atuam sobre uma base procedimental formada de meios que necessitam 
adequar-se aos fins de forma tão rica quanto a diversidade dos direitos materiais a serem tutelados.

Daí afirmar-se, por exemplo, a existência do processo externamente à jurisdição, como ocorre com o processo administrativo, na lição de $\left(\right.$ BACELLAR FILHO, 1998) ${ }^{12}$. Isso porque no momento em que a Constituição Federal utiliza a expressão "processo administrativo" acredita-se que tal opção vai muito além de uma simples preferência terminológica, admitindo a existência do regime jurídico processual nas atividades administrativas desprovidas de jurisdição, mas baseadas em atos procedimentais, contraditório e ampla defesa.

E é nesse sentido que se interpreta, também, a afirmativa de (FAZZALARI, 1996) ${ }^{13}$ quando ele retira o instituto da jurisdição do conceito de processo e diz que este consiste, na realidade, no procedimento em contraditório (princípio fundamental), pois na base de qualquer providência ou medida a ser tomada através dele, sempre estará o procedimento.

Percebe-se, desse modo, que a influência dos direitos fundamentais sobre a teoria e a prática processuais é tão profunda que não apenas os conceitos de tutela jurisdicional e de processo tendem a ser redefinidos como também a própria teoria processual necessita ser pensada nesta nova dimensão. Não se afigura razoável, por exemplo, segundo a perspectiva constitucional, que a condição para o exercício do direito de

12 De acordo com Bacellar Filho (1998, p. 47): "De procedimentos administrativos podem resultar processos administrativos desde que caracterizada situação demandante de participação dos interessados em contraditório. Saliente-se que o conceito de processo e de procedimento administrativo não está calcado em questão abstraída do sistema jurídico. Não se trata de tomar a posição mais justa ou mais conveniente à ideologia do intérprete. Funda-se, mormente, no Texto Constitucional que revela sua opção quando no art. $5^{\circ}$, inc. LV, junge o conceito de processo administrativo a litigantes e acusados, sob a égide do contraditório e da ampla defesa com os meios e recursos a ela inerentes. A partir disto compreende-se que, quando a constituição federal de 1988 adota a expressão processo administrativo, a escolha vá além de preferência terminológica. Comporta o reconhecimento expresso da exigência do regime jurídico processual nas atividades administrativas delimitadas pela Carta Magna".

13 Conforme o pensamento de Fazzalari (1996, p. 7): “O processo é procedimento em contraditório, pois antes de qualquer medida, providência ou remédio, sempre se localizará o procedimento". 
ação constituída pelo interesse de agir necessite sempre depender de adequação procedimental à estrutura do $\mathrm{CPC}$ e não ao direito material a ser tutelado, como será analisado adiante.

Hoje, dessa feita, acredita-se não existir paradoxo entre a especialização de procedimentos e o processualismo científico, embora o Livro IV de nosso Código de Processo Civil não tenha chegado a ser redigido pelo então ministro Alfredo Buzaid, exatamente porque este entendia que os procedimentos especiais eram a parte da ciência processual que não havia evoluído, acreditando tratarem-se de antigos vestígios do período procedimentalista sincrético abandonado pela evolução da teoria do direito processual civil, como explica (BAPTISTA DA SILVA, 1998a) ${ }^{14}$. Hoje, entretanto, não há dúvida de que procedimentos especiais como o mandado de segurança, o despejo e a reintegração de posse, são altamente efetivos e muitas vezes resultantes dos "lobbys" de determinadas setores econômicos.

Assim, a chamada "especialização de procedimentos" não deve ser concebida como a necessidade da criação de um procedimento especial previsto em lei para cada espécie de direito, o que não seria factível pela diversidade de direitos existentes - embora conveniente, na medida do possível - mas sim como a necessidade de adaptar-se os procedimentos segundo os casos concretos conforme a demanda dinâmica dos respetivos feitos. Logo, a especialização de procedimentos ora defendida não se liga apenas ao raciocínio legislativo de justificação das normas, mas sim, e principalmente, à lógica operativa de aplicação e adaptação dos procedimentos às vicissitudes das situações concretas.

14 Segundo Baptista da Silva (1998a, p. 28): “Alguém poderia objetivar contra nosso argumento de que o Código de 1973 tende para a universalização da ordinariedade, alegando que o legislador dedicou aos Procedimentos Especiais todo um livro do Código, onde tratou justamente dos procedimentos que fogem à ordinariedade. Esta objeção poderia, à primeira vista, impressionar. Contudo, há circunstâncias históricas e manifestações doutrinárias que, antes de dar peso ao argumento, confirmam nossa conclusão. Em verdade, o inteiro Livro IV de nosso Código não foi sequer redigido por seu autor, e os Procedimentos Especiais que ele abriga não passam para a doutrina dominante em nosso país de vestígios arcaicos de institutos e princípios medievais apenas conservados em nosso direito contemporâneo por força da tradição." 
Desse modo, a busca por adequação procedimental, classicamente concebida como um dos elementos constitutivos do interesse de agir que é condição da ação - ao lado do binômio necessidade/utilidade do pronunciamento jurisdicional - deixa de estar ligada à formalidade dos procedimentos previstos pelo CPC, para numa perspectiva jusfundamental, adequar-se ao direito material e às situações reais a serem tuteladas: adequar-se aos fins de tutela dos direitos e não aos meios constituídos pela rígida estrutura do CPC.

Portanto, a influência dos direitos fundamentais, as necessidades da sociedade de massas e a busca por sensatez científica, têm levado os estudiosos a reconhecer os objetivos da efetividade, do acesso à justiça e da instrumentalidade como atuais norteadores do desenvolvimento do direito processual civil. Acima da autonomia da relação jurídica processual em relação ao direito material está a própria efetividade da jurisdição, cujo aperfeiçoamento passa necessariamente pela via do processo. Sem que o direito possa se fazer sentir na vida prática dos litigantes, não há que se falar numa verdadeira evolução da teoria processual.

A teoria processual é diariamente testada no cotidiano forense. A grande missão do processo atual é trazer resultados com significativa segurança. $\mathrm{O}$ verdadeiro progresso da ciência processual não diz mais respeito à evolução de si mesmo, senão da sua íntima ligação com a prestação da justiça. Não há mais que se falar em evolução da teoria processual sem que haja resultados para os litigantes.

É nesse sentido que as últimas modificações do Código de Processo Civil demonstram grande preocupação com o respeito à dignidade da prestação da justiça (CPC, art. 14, V, § único), bem como com a flexibilização e desburocratização das regras processuais com vistas às mais adequadas aplicações do direito material.

O processo é instrumento da jurisdição e a jurisdição é instrumento para a satisfação dos direitos. Logo, o processo é meio para a jurisdição, que, por sua vez, é meio para o fim da prestação da justiça. Não é razoável, sob o ponto de vista lógico nem sob o aspecto ético, que premissas científicas processuais desatualizadas impeçam o poder judiciário de tutelar os direitos com efetividade. 
Portanto, esse amadurecimento flexibilizador do direito processual civil coaduna-se com a volta do sincretismo processual, com a prática de atos de execução e cognição em um mesmo procedimento. A admissão do sincretismo volta a reunir concepções de diferentes origens, com o fim de contribuírem estas para o aperfeiçoamento do instrumento constituído pelo processo, na medida do possível.

Não há mais que se falar, dessa maneira, na impossibilidade de estudar e desenvolver cientificamente o direito processual civil, aplicando-se técnicas conjuntas de cognição e execução. Pelo contrário, a possibilidade de se obterem decisões de mérito de forma generalizada, através de cognição sumária e produção de efeitos executivos fáticos imediatos é essencial para que se tutele a urgência.

Constata-se, dessa forma, que a dialética histórica da teoria processual foi marcada, originalmente, pelo sincretismo e pelo procedimentalismo, embora mais tarde o aperfeiçoamento e a busca pela autonomia do processo tenham provocado uma preocupação excessiva da ciência processual consigo mesma e com elementos teóricos próprios, de maneira que a sua atual busca por efetividade demanda maior flexibilidade e, portanto, sincretismo.

É impossível não considerar, desse modo, a influência dos direitos fundamentais no âmbito do processo, pois os estudos dedicados a encontrar formas para o aperfeiçoamento da prestação jurisdicional possuem embasamento invariável, antes de tudo, em um direito constitucional elementar: o direito fundamental è efetividade do processo.

Nesse sentido, o inciso XXXV do artigo $5^{\circ}$ da Constituição Federal, ao explicitar que a lei não pode excluir eventual lesão ou ameaça a direito da apreciação do poder judiciário, está a garantir de modo enfático o direito fundamental à prestação jurisdicional efetiva; aos resultados através do processo e da jurisdição. Como o julgamento de mérito tem importância prática apenas se o direito material for realizado, é forçoso concluir que o próprio direito à prestação jurisdicional, nessa perspectiva, se revela como sendo o direito à sua efetividade, seja ela reparatória, ressarcitória ou preventiva; urgente ou definitiva. 
É a influência do inciso XXXV do artigo $5^{\circ}$, a respeito dos direitos fundamentais à inafastabilidade do controle jurisdicional e à efetividade do sistema processual que, mesmo antes do advento do inciso LXXVIII do mesmo dispositivo, trazido pela Emenda Constitucional n. 45 - acerca da duração razoável do processo - já permitia concluir serem, boa parte das últimas reformas constitucionais e também do CPC, modificações de natureza essencialmente didática, e não essencialmente modificadoras do sistema jurídico.

Isso porque as reformas se dedicaram, muitas vezes, a explicitar o alcance que as disposições da constituição federal já possibilitava na busca por efetividade. Assim, a necessidade constitucionalmente prevista de obterem-se resultados efetivos modificou inclusive os objetivos do processo.

O grande objetivo do processo civil clássico era o atingimento do status jurídico formado pela coisa julgada material acerca da declaração a respeito de qual das partes possuía razão no mérito, pois se supunha que através daquela compor-se-iam as lides. Hoje, entretanto, tem se aceitado possuírem, os meios processuais, o objetivo de proporcionarem o fim constituído pelo respeito ao ordenamento jurídico através de uma prestação da justiça tempestiva e necessariamente adequada ao direito material, sem a qual não há que se falar em tutela jurisdicional, pois tão ou mais importante que a declaração dos direitos é a sua satisfação, sua efetividade.

\subsection{O Ser e o Dever ser Processual: a importância da lógica causal e dos estudos essencialmente descritivos}

O desenvolvimento da ciência jurídica, especialmente do direito processual, nos últimos anos tem reclamado variação de pesquisa diversa daquela meramente bibliográfica (POSNER, 2008), considerando a psicologia, a sociologia e o direito.

Tanto os estudos interdisciplinares da teoria comportamental quanto da teoria fenomenológica merecem atenção especial (POSNER, 2008), pois a tomada de decisões e a definição de estratégias não consegue atingir resultados no mundo dos fatos sem que diversas variáveis fáticas sejam consideradas. 
Daí a ideia: para pensar e compreender a aplicação da norma processual mediante critérios valorativos não é necessário abandonar a tradicional lógica normativa, do dever ser normativo, mas também se deve considerar, talvez até com maior ênfase conforme o objetivo a ser atingido, a lógica causal do ser. A mesma lógica da medicina ou da matemática.

Além de conhecer com detalhes os precedentes aplicáveis, importará saber como o julgador pensa; qual a sua postura ideológica; quem são as partes; quem são seus procuradores; quais as suas posturas ideológicas; como funcionam o cartório ou o tribunal.

Tudo depende de aceitar-se o estudo da ciência jurídica também a partir de uma perspectiva meramente descritiva e não prescritiva do dever ser jurídico. Tal atitude visa encontrar com maior clareza os motivos do descumprimento do próprio dever ser jurídico, ao invés do clássico apego ao mero discurso de respeito à determinada interpretação da norma.

Constitui uma limitação indesejada o apego à ideia de que a teoria do fato jurídico destinou o estudioso do direito a considerar apenas as relações jurídicas; a acreditar que esse é o objeto do estudo do direito (relações jurídicas).

É compreensível que a identificação do estudo do direito com o estudo das relações jurídicas - a partir da teoria do fato jurídico - tenha ocorrido quando se buscava autonomia no sistema e das disciplinas jurídicas, tais como o processo, mas hoje isso não é mais plausível, vez que a autonomia das disciplinas jurídicas já foi conquistada.

Como obras com esse enfoque, e que merecem maior atenção da comunidade científica, pode-se destacar, além dos estudos de POSNER, os estudos da Escola de Chicago em convênio com instituições européias, especialmente o Acesso à Justiça (CAPPELLETTI; GARTH, 1988) e The sense of apropriateness (GUINTER, 1993), dentre outras.

\section{Conclusão}

Assim, é preciso reconhecer que tanto o poder judiciário quanto os estudiosos teorizadores do processo não podem deixar de considerar o di- 
reito fundamental à efetividade, de tal modo que a proteção dos demais direitos depende do seu respeito.

Sob esse prisma causal, a efetividade da jurisdição revela-se como sendo o mais importante dos direitos fundamentais, afirmativa essa corroborada por Marinoni (1993) $)^{15}$.

Percebe-se, portanto, que o direito constitucional à prestação jurisdicional é essencial à efetividade do direito material, uma vez que esse direito, diante de situações de agressão ou de ameaça, sempre necessita realizar-se plenamente.

É por essa razão que o direito à efetividade da prestação jurisdicional, ao menos sob esse prisma - da preocupação com a garantia - ser concebido como o mais importante dos direitos, exatamente por representar o direito a tutelar os demais direitos, na lição de Couture (2003, p. 57).

Dessa maneira, em suma, o advento dos direitos fundamentais não apenas modificou o direito processual teórica e operativamente, como também impôs respeito ao direito à efetividade da prestação jurisdicional.

Juntamente com a interpretação ora realizada acerca dos direitos fundamentais para o fim de possibilitar a consideração de valores inclusive entre regras processuais, esses são embasamentos constitucionais fornecidos ao delineamento de uma teoria constitucional do processo ideologicamente consciente.

Nesse desiderato, o que se propõe é uma intepretação que considere não apenas o dever ser processual, mas também o ser processual, pois a tomada de decisões e a definição de estratégias não consegue atingir re-

15 Segundo Marioni (1993, p. 7): "Para resumir, basta evidenciar que há direito fundamental à tutela jurisdicional efetiva, tempestiva e, quando houver necessidade, preventiva. A compreensão desse direito depende da adequação da técnica processual aos direitos, ou melhor, da visualização da técnica processual a partir das necessidades do direito material. Se a efetividade (em sentido lato) requer adequação e a adequação deve trazer efetividade, o certo é que os dois conceitos podem ser decompostos para melhor explicar a necessidade de adequação da técnica às diferentes situações de direito substancial. Pensando-se a partir dai fica mais fácil visualizar a técnica efetiva, contribuindo-se para sua otimização e para que a efetividade ocorra do modo menos gravoso ao réu".(grifou-se). 
sultados no mundo dos fatos sem que diversas variáveis fáticas e ideológiocas sejam consideradas sob o prisma empírico.

\section{Referências}

ALEXY, Robert. Teoria de Los derechos fundamentales. Madrid: Fareso, 1993.

ASSIS, Araken de. Manual do Processo de Execução. São Paulo: RT, 2008.

BACELLAR FILHO, Romeu Felipe. Princípios constitucionais do processo administrativo disciplinar. São Paulo: Max Limonad, 1998.

BARBOSA MOREIRA, José Carlos. Temas de direito processual.

7. série. São Paulo: Saraiva, 2001.

BECKER, Alfredo Augusto. Carnaval tributário. 2. ed. São Paulo: Lejus, 2004.

BEDAQUE, José Roberto dos Santos. Direito e processo: influência do direito material sobre o processo. São Paulo: Malheiros, 2001.

BEDAQUE, José Roberto dos Santos. Tutela Cautelar e Tutela Antecipada: tutelas sumárias e de urgência - tentativa de sistematização. 3. ed. São Paulo: Malheiros, 2003.

BERGER, Jefrey. The Origin of formalism in social science. Chicago: University Press, 1981.

BONAVIDES, Mauro. Curso de direito constitucional. São Paulo: Malheiros, 1996.

BUENO, Cássio Scarpinella. Direito, interpretação e norma jurídica: uma aproximação musical do direito. Revista de Processo, São Paulo, n. 111, RT, p. 223-242, 2001.

BULOW, Oskar Von. La Teoria de Las Excepciones Procesales y Los Presupuestos Procesales. Buenos Aires: EJEA, 1964. 
CADERMATORI, Luiz Henrique Urquhart. Discricionariedade Administrativa no Estado Constitucional de Direito. Curitiba: Juruá, 2003.

CALAMANDREI, Piero. O Processo Como Jogo. Tradução de Roberto B. Del Claro. Revista Gênesis, Curitiba, n. 23, p. 191-290, 2002.

CALMON DE PASSOS, João José. Uma Nova teoria geral do processo? Informativo INCIJUR, Joinville, n. 54, janeiro, 2004.

CALMON DE PASSOS, João José. Função social do processo. 2002.

Disponível em: <http://jus.com.br/artigos/3198/funcao-social-doprocesso>. Acesso em: 14 nov. 2014.

. Instrumentalidade do Processo e Devido Processo Legal.

Revista de Processo, São Paulo, n. 102, RT, p. 55-67, 1998

CALMON FILHO, Petrônio. Argüição realizada no programa

"Defenda sua Tese", na TV Justiça, em 14 de junho de 2006.

. (Org.). Cadernos IBDP: série propostas legislativas. Brasília,

DF: Instituto Brasileiro de Direito Processual, 2003. (v. III)

CANOTILHO, José Joaquim Gomes. Direito constitucional. Coimbra: Almedina, 1989.

CAPPELLETTI, Mauro; GARTH, Bryant. Acesso à justiça. Tradução de Ellen Gracie Northfleet. Sergio Antonio Fabris Editor, Porto Alegre: 1988.

CHIOVENDA, Giuseppe. Principii di diritto processuale civile.

Napoli: Casa Editrice Dott. Eugenio Jovene, 1965.

CINTRA, Antônio Carlos de Araújo e outros. Teoria geral do processo. São Paulo: Malheiros, 1997.

COMPARATO, Fábio Konder. A Afirmação histórica dos direitos fundamentais. São Paulo: Saraiva.

COSSIO, Carlos. La Teoria egológica del derecho. Buenos Aires: Abeledo-Perrot, 1963. 
COUTURE, Eduardo J. Fundamentos del derecho procesal civil. Buenos Aires: Depalma, 1958.

COUTURE, Eduardo J. Introdução ao estudo do processo civil. Tradução de Hiltomar Martins Vieira. Belo Horizonte: Líder, 2003. DIDIER, Fredie. Recurso de Terceiro: juízo de admissibilidade. São Paulo: RT, 2002.

. Pressupostos processuais e condições da ação. São Paulo: Saraiva, 2005.

DINAMARCO, Cândido Rangel. A Instrumentalidade do processo. 11. ed. São Paulo: Malheiros Editores, 2003.

DREIER, Ralf. Recht - moral - ideologie. Frankfurt: Suhrkamp, 1981. DWORKIN, Ronald. Uma questão de princípio. São Paulo: Martins Fontes, 1999.

FAZZALARI, Elio. Processo: teoria generale. Novíssimo Digesto Italiano, Torino, V, XIII, 1996.

FERREIRA FILHO, Manoel Gonçalves. A aplicação imediata das normas definidoras de direitos e garantias fundamentais. Revista da Procuradoria Geral do Estado de São Paulo, São Paulo, n. 29, 1988. FREUD, Sigmund. Dostoyevski y el Parricidio. In: Obras Completas Tomo III. Madrid: Tecnos, 1980.

FIGUEIRA JÚNIOR, Joel Dias. Comentários à novíssima reforma do CPC. Rio de Janeiro: Forense, 2003.

GÓES, Gisele Santos Fernandes. Princípio da proporcionalidade no processo civil. São Paulo: Saraiva, 2004.

GUERRA FILHO, Willis Santiago. Processo constitucional e direitos fundamentais. 3. ed. São Paulo: Celso Bastos Editor, 2003.

GUINTER, Klaus. The Sense of apropriateness. Albany: State University of New York Press, 1993. 
. Un Concepto normativo de coherencia para una teoria de la argumentación jurídica. Tradução de Juan Carlos Velasco Arroyo. Sevilha: Tecnos, 1995.

HART, Herbert. O Conceito de direito. Lisboa: Fundação Calouste Gulbenkian, 2001.

HESSE, Konrad. A Força normativa da constituição. Tradução de Gilmar Ferreira Mendes. Porto Alegre: Sérgio Antonio Fabris, 1991. HOBBES, Thomas. O Leviatã, ou a matéria, forma e poder de um estado eclesiástico e civil. São Paulo: Ícone, 1997.

KANT, Immanuel. Crítica da razão pura. Tradução de Valerio Rohden e Udo Moosburger. São Paulo: Nova Cultural, 1996. (Coleção Os Pensadores)

KELSEN, Hans. Teoria pura do direito. São Paulo: Martins Fontes, 1997.

LACERDA, Galeno. Despacho saneador. 2. ed. Porto Alegre: Sérgio Antônio Fabris Editor, 1985.

LAMY, Eduardo de Avelar. A Manutenção dos embargos infringentes pela reforma do cpc e a restrição indireta trazida pelo novo $\S 4^{\mathrm{a}}$ do art. 515. Revista de Processo, São Paulo, n. 137, RT, p. 128-133, 2006.

. Flexibilização da tutela de urgência. Curitiba: Juruá, 2007.

. Prisão penal e coerção processual civil. Revista Gênesis, Curitiba, n. 19, p. 38-51, 2001.

. Repercussão geral no Recurso Extraordinário: a volta da argüição de relevância? In: WAMBIER, Teresa Arruda Alvim et al. (Org.). Reforma do Judiciário. São Paulo: RT, 2005.

. Súmula vinculante: um desafio. Revista de Processo, São Paulo, n. 120, RT, p. 112-137, 2005.

LASSALE, Ferdinand. A Essência da constituição. 3. ed. Rio de Janeiro: Líber Júris, 1998. 
LUCON, Paulo Henrique dos Santos. Garantia do tratamento paritário das partes. garantias constitucionais do processo civil. Coord. José Rogério Cruz e Tucci. São Paulo: RT, 2004.

LUHMANN, Nicklas. Sociologia do direito. Rio de Janeiro: Tempo Brasileiro, 1983.

LUNO, Antônio Enrique Perez. Derechos humanos, estado de derecho y constitucion. 5. ed. Sevilha: Tecnos, 1994.

. Los Derechos fundamentales. Madrid: Tecnos, 1993.

MARINONI, Luiz Guilherme. Efetividade do processo e tutela de urgência. Porto Alegre: Sérgio Fabris, 1993.

MARINONI, Luiz Guilherme. Tutela inibitória. 1. ed. São Paulo: Revista dos Tribunais, 1998.

. Técnica processual e tutela dos direitos. São Paulo: Revista dos Tribunais, 2004.

NERY JÚNIOR, Nelson. Princípios do processo civil na Constituição Federal. 6. ed. São Paulo: RT, 2000.

OLIVEIRA, Carlos Alberto Álvaro de. Do Formalismo no processo civil. São Paulo: Saraiva, 2003.

PISANI, Andréa Proto. Breve premessa ad um corso sulla giustizia civile. appunti sulla giustizia civile. Bari: Caducci, 1982.

PONTES DE MIRANDA. Tratado das Ações. São Paulo: Bookseller, 1997. (v. V)

PORTANOVA, Rui. Princípios do processo civil. Porto Alegre: Livraria do Advogado, 2005.

ROUSSEAU, Jean-Jacques. O Contrato social. São Paulo: Martins Fontes, 1999.

POSNER, Richard. How judges think. Cambridge, Massachusetts, London: Harvard University Press, 2008.

SARLET, Ingo Wolfgang. A Eficácia dos direitos fundamentais. Porto Alegre: Livraria do Advogado, 2003. 
SEN, Amarthia. Desenvolvimento como liberdade. São Paulo: Companhia das Letras, 2003.

SILVA, Luiz Afonso Virgílio da. O Proporcional e o razoável. RT 798, p. 89-102, abril de 2002.

SILVA, Tarcísio Geroleti. A Efetividade do processo à luz do princípio da proporcionalidade. Monografia apresentada no curso de pósgraduação da UNERJ e FURB: 2003.

SILVA, Jaqueline Mielke. O Direito processual civil como instrumento de realização de direitos. Porto Alegre: Verbo Jurídico, 2005.

SILVA, Ovídio Baptista da. Curso de processo civil: processo cautelar (tutela de urgência). 2. ed. São Paulo: RT, 1998. (v. III)

SILVA, Ovídeo Baptista da. Curso de direito processual civil. São Paulo: RT, 1998a.

. Jurisdição e execução. São Paulo: RT, 1998b.

. Processo e ideologia. São Paulo: RT, 2000.

TESHEINER, José Maria. Pressupostos processuais e nulidades no processo civil. São Paulo: Saraiva, 2000.

WAMBIER, Teresa Arruda Alvim. Fungibilidade de meios: uma nova dimensão do princípio da fungibilidade. aspectos polêmicos e atuais dos recursos cíveis e de outras formas de impugnação às deciões judiciais. São Paulo: RT, 2001. (v. 4)

2004.

. Nulidades do processo e da sentença. 5. ed. São Paulo: RT, WOLKMER, Antonio Carlos. (Org.). Fundamentos de história do direito. 2. ed. Belo Horizonte: Del Rey, 2002.

Eduardo de Avelar Lamy é Mestre e Doutor em Direito Processual Civil pela Pontifícia Universidade Católica de São Paulo (PUC/SP). Advogado. Professor Adjunto da Universidade Federal de Santa Catarina (UFSC), nos cursos de 
graduação e pós-graduação strito sensu (Mestrado e Doutorado). Diretor-Geral da Escola Superior da Advocacia - ESA/OAB/SC. Membro e Secretário Adjunto do Instituto Brasileiro de Direito Processual (IBDP). Membro da Academia Brasileira de Direito Processual Civil (ABDPC).

Email: edulamy@hotmail.com e lamy@melloesouza.adv.br

Endereço profissional: Universidade Federal de Santa Catarina. Campus Universitário, s/n, Florianópolis, SC, Brasil 
